\title{
How to Fix the Inefficiency of Global Cap and Trade
}

\section{PETER CRAMTON AND STEVEN STOFT ${ }^{1}$}

Peter Cramton is Professor of Economics at the University of Maryland and an expert on market design; Steven Stoft is Director of the Global Energy Policy Center and the author of Carbonomics.

(๑) De Gruyter ages countries to choose abatements that are inefficiently low. Countries act out of self-interest, including, in some cases, a desire to profit from trading carbon credits. Such strategies have been overlooked because global cap and trade is assumed to share the desirable properties of national cap and trade. But coal-burning countries have acted much like coal-burning power plants would act if they were allowed to choose their own targets.

Modeling global cap and trade as a game based on self-interest reveals the behaviors that have led to the breakdown of the Kyoto approach. The game is so uncooperative that it may even increase total emissions relative to what would occur without any global climate policy. ${ }^{2}$

Having countries select a global cap rather

cate responsibility for the cap. This is best seen by comparing two idealized policy games, one that selects a global cap and one that directly selects a global price. If all countries were identical, the two policy games would both produce the optimal outcome. However, ordinary national differences cause the capping game to fail, while the price-target game produces the optimal outcome.

But even the global-price game fails when challenged with the rich-poor divide that has plagued climate negotiations. Introducing a Green Fund can, however, rescue the carbonprice game. Properly harnessed, the Green Fund, induces cooperation from both sides of the rich-poor divide.

INTERNATIONAL CAP AND TRADE than national targets would improve the cap, but then the difficulty becomes deciding how to allo-

Tnternational cap and trade suffers from the lack of a capping authority, so countries select The Economists' Voice http://www.degruyłer.com/view/j/ev April, 2012 
their own targets, with the help of a little international arm twisting, which has been ineffective.

To understand this game, first consider what would happen without it. There would still be a game-the well-known, public-goods game (a multi-player prisoner's dilemma) in which each country chooses its level of abatement, a public good. ${ }^{3}$ For example, suppose there are ten identical countries which value global abatement at $\$ 10$ per ton abated. The total global benefit of abating a ton is then $\$ 100$. So each country should abate until the marginal cost of abatement is $\$ 100$ per ton. But instead, self-interested countries realize that they get only one tenth of the global benefit, and they stop abating at a marginal cost of only $\$ 10$ per ton, so the national policies are ten times too weak.

Now, change the game by letting nations choose targets instead of abatements and by introducing carbon trading. Any country that falls short of its target can buy credits from a country that exceeds its target. This makes abatement efficient to the extent it occurs, unlike in the public-goods game. But in a world with identical countries, there would be no trade, and the incentive to choose a target would be identical to the incentive to abate in the public-goods game. Hence, with identical countries, international cap and trade makes no difference. When countries differ, total abatement may either be higher or lower than in the public-goods game. ${ }^{4}$ Cap and trade solves the lack-of-trading inefficiency, but it does nothing to reduce the muchworse publicgoods inefficiency.

Another result provides an additional warning. If countries can subsidize or tax the use of fossil fuel, thereby distorting the carbon price, then national abatements under cap and trade will be identical to national abatements under the public-goods game. ${ }^{5}$ More ambitious countries will still buy credits from less ambitious countries (which profit from trading) but with no effect on national abatements. Even the efficiency of trading is lost.

\section{WHY A PRICE COMMITMENT IS SUPERIOR}

Alobal cap is no harder to agree on than Aa global price. But, as noted, the cap has no obvious method of allocation, while a global price is associated with a widely accepted method of allocating responsibility. We illustrate this with a pair of games, one of which leads to the Green-Fund game.
Although the cap-and-trade game yields a discouragingly low global cap even with identical countries, two simple games select the optimal cap or price commitment under the same circumstances. These are games of "voting" for a collective commitment.

By "vote" we mean that each country names its preferred level of global commitment. The outcome of voting is defined to be the leaststrict preferred commitment, the one that determines the minimum price or highest cap. While accepting the least-strict commitment may sound weak, the result is the globally-optimal price for carbon. Voting succeeds because each country realizes that, if its vote is accepted, its vote will determine abatement in every country. So, unlike with global cap and trade, adopting a stronger policy does not just impose a national burden that mainly benefits others. Instead, adopting a stronger policy causes all others to abate more, which benefits the voting country. Hence voting for a collective commitment succeeds, where choosing individual commitments fails.

Because the Kyoto approach focused on locking in targets rather than establishing an organization, the idea of adopting a voting rule 
may seem unusual. Yet, voting is how international organizations operate, and it is the hope of locking in a 40-year solution at the start that is unprecedented. In fact, the International Energy Agency was established with voting rules that are among the most complex and innovative of any international organization. ${ }^{6}$ And, its creation took less than a year, start to finish. After establishment, it took under two years to vote in an oil (carbon) price floor. (A quantity agreement was proposed first, but failed because, just as with cap and trade, nothing approaching a fair allocation of quantity commitments could be discovered.)

With the voting method just described and identical countries, both a global cap and a global price would lead to an optimal treaty, because, with identical countries, there is an obvious way to divide responsibility. Each country gets its proportional share of the cap. But when countries differ by climate, history, geography and type of energy resources, there is no obvious way to allocate a global cap, and the capping game will end in disagreement. There is, however, a well-accepted focal point for allocating the burdens of a collective price target-each country should commit to the global price. This is efficient; it requires similar effort levels; it does not require paying other countries for carbon credits, and it is by far the most obvious rule. Consequently, there is a good chance that the pricing game will end in agreement.

At this point, we must address a persistent confusion. Commitment to a global price target does not require national carbon taxes, or even fossil-fuel taxes. Cap and trade can be used to meet a price target, so all countries would be free to adopt national cap-and-trade policies with or without international trading. The uncertainty of such carbon prices could be handled in various ways, some quite analogous to the trading of carbon credits.

We recommend a global price target, because equal pricing is a focal point in the global climate game. Even those favoring caps hold up equal prices as the justification for trading carbon. However, as strong as this focal point is, it cannot stand up to the asymmetry that has torn apart international climate negotiations-the gulf between rich and poor. To overcome this gulf, a Green Climate Fund was created in 2010 (although not funded), and this may serve as an additional focal point.

\section{THE GREEN-FUND GAME}

The Green-Fund game described here proI vides incentives for wealthy countries to make strong Green-Fund commitments and for poor countries to reciprocate by accepting a higher global price target. The Fund is designed to maximize the carbon price that can be agreed. Countries will receive Green-Fund payments of $G \cdot \Delta E \cdot P^{T}$, where $G$ determines the strength of the Green Fund; $\Delta E$ is a country's emissions shortfall relative to the global percapita average, and $P^{T}$ is the global price target. Note that high-emission countries will have a negative $\Delta E$, and hence will make payments rather than receive them.

The game proceeds in three stages. First, a group of neutral countries chooses $G$ with the goal of maximizing the carbon price target that will be agreed in stage two. Second, the countries interested in cooperating vote for $P^{T}$, as described above. Third, the cooperating countries price carbon and make and receive Green-Fund payments.

The first stage could be carried out as follows. Countries with the least Green-Fund involvement-those with emissions near the average-name their desired choice for $G$. The 
median of these choices is selected. Using the median value guarantees that outliers will have little influence.

These countries will be concerned mainly with achieving their climate objective because they participate so little in the Green Fund. As the final $P^{T}$ cannot be higher than their vote for $P^{T}$, they will have no concern that the final $P^{T}$ will be too high. Instead they will only worry that it may be too low and will overrule their preference.

How can they achieve the highest $P^{T}$ ? A higher value of $G$ makes a high $P^{T}$ more appealing to poor countries because $G$ multiplies $P^{T}$ in the Green-payment formula. Similarly a higher $G$ makes rich countries favor a lower $P^{T}$. So those who set $G$ will raise $G$ to the point where poor countries will vote for as high a $P^{T}$ as rich countries.

The second stage sets $P^{T}$ at the lowest vote of the cooperative parities. The new feature is the selection of the "cooperative parties." Initially, the group might be limited to a handful of countries that trust each other to cooperate. Later, when the group is expanded to maximize the strength of the policy, the cooperative parties would be defined as those voting for the highest
$P^{T}$. And, the size of the group would be defined as the smallest size that encompassed, say, 70 percent of carbon emissions.

Again, it is important to recall that countries will name a much higher price when that price applies to the entire group and not only to themselves. Also note that setting a global price higher than some countries think is sensible would encourage defections, and the most important ingredient for success is cooperation. In any case, selection of $P^{T}$ should occur periodically, so that no one feels they must lock themselves into a future that is scientifically and politically unknowable. Periodically resetting $P^{T}$ will allow countries to be far less conservative in their commitments.

The third stage is rather mechanical, but includes two additional features favoring cooperation and a strong climate policy. First, the use of $\Delta E$ in the Green-Fund formula means that every country will be motivated to reduce their percapita emissions in order to minimize their contributions to, or maximize their receipts from, the Green Fund. Second, countries on the receiving end of the fund will not be allowed to collect unless they have implemented the carbon price and allowed verification.
This game was tested on a model based on the emissions and populations of China, India and the U.S. The model was designed around an assumption that the currently desired carbon price is about $\$ 30$ per ton and that such a price would reduce emissions by 20 percent. India was modeled as wanting a global carbon global price of only $\$ 10$ per ton, while the U.S. and China would each set the global price at \$31/ ton, all based on self-interest without a Green Fund $(G=0)$.

As China has average emissions, it selects $G$, which results in India and the U.S. voting for a carbon price of $\$ 26.40$, while China sticks with its vote of $\$ 31$. The low votes prevail.

In this model, the no-policy, public-goods abatement would be 8.4 percent, global cap and trade would produce an abatement of 6.5 percent, the Green-Fund game yields an abatement of 18.2 percent, and the optimal abatement is 19.6 percent. The example was not calibrated to produce such answers; it was simply designed around actual emissions and the values $\$ 30 /$ ton, a 20 percent abatement and a $\$ 10$ vote by India.

The most significant deviation from reality in this model is the number of countries. As that 
number increases, the public-goods problem becomes worse, so the discrepancy between the uncooperative public-goods and cap-and-trade games and the cooperative Green-Fund game is likely understated.

Because the Green-Fund game is based on an efficient price instead of a myriad of idiosyncratic subsidies, it is remarkably inexpensive. For the U.S., the cost of abatement is $11.5 \mathrm{k} /$ person per day, while the cost of the Green Fund is $4 \$ /$ capita-day, which comes to a total of $\$ 17$ billion/year. The cost for China is 3.2 $\$$ /capita-day. The cost of abatement to India is $1 \$$ /capita-day, and Green-Fund revenues are 1.2\$/capita-day. So India comes out ahead even without considering climate benefits.

While the Green-Fund game provides a far better approach than cap and trade backed by arm twisting, we believe there is a more fundamental lesson. In the most uncooperative of games-a prisoner's dilemma with many players facing distant and uncertain payoffs-the problem to focus on is cooperation. To solve this problem, we should look to the science of cooperation and to economic models of self-interest, and design a treaty that encourages cooperative behavior
Letters commenting on this piece or others may be submitted at http://www.degruyter.com/ view/j/ev?tab=services

\section{NOTES}

1. Their research on climate policy can be found at www.global-energy.org and www.cramton.umd.edu/ papers/climate

2. See Helm (2003)

Policies must specify and measure emissions, but abatement is a convenient variable for analysis equal to business-as-usual emissions minus actual emissions.

4. See Helm (2003)

5. See Godal and Holstmark (2011).

6. "The History of The International Energy Agency: The First Twenty Years," Richard Scott, IEA publication.

\section{REFERENCES AND FURTHER READING}

Cooper, Richard N. (2008) "The Case for Charges on Greenhouse Gas Emissions," The Harvard Project on International Climate Agreements, Discussion Paper 08-10.

Cramton, Peter and Steven Stoft (2010) "Price Is a Better Climate Commitment," The Economists' Voice, 7:1. Available at: http://www.degruyter. com/view/j/ev.2010.7.1/ev.2010.7.1.1718/ ev.2010.7.1.1718.xml?
Cramton, Peter and Steven Stoft (2012) "Global Climate Games: How Pricing and a Green Fund Foster Cooperation," Economics of Energy \& Environmental Policy, 1:2. Available at: www. iaee.org/en/publications/eeepjournal.aspx and www.global-energy.org/lib/11-01.

Godal, Odd and Bjart J. Holtsmark (2011) "Permit Trading: Merely an Efficiency-Neutral Redistribution Away from Climate Change Victims?" Scandinavian Journal of Economics, 113: 784-797.

Helm, Carsten (2003) "International Emissions Trading with Endogenous Allowance Choices," Journal of Public Economics, 87: 2737-2747.

Holtsmark, Bjart J. and Dag Einar Sommervoll (2008) "International Emissions Trading in a Non-cooperative Equilibrium," Discussion Papers 542, Research Department of Statistics Norway.

Stoft, Steven (2009) "Flexible Global Carbon Pricing: A Backward-Compatible Upgrade for the Kyoto Protocol," European University Institute Working Paper No. RSCAS 2009/35. 